\title{
LOST IN TRANSLATION: \\ UNDERSTANDING EXPERTISE IN MEDICAL AND HEALING ENCOUNTERS
}

\author{
Philippa Miskelly
}

\begin{abstract}
The dominance of orthodox medicine as the principle health care system in Western-style societies is largely due to ideas constructed around individualistic ideologies as well as the privileging of scientific knowledge and technological advances. This has led to an environment where expertise relating to health and illness is often considered the domain of the orthodox medical profession as opposed to alternative/complementary practitioners and patients. My research into patients combining both orthodox and alternative/complementary medicines reveals a complex web of beliefs where patients describe their expertise in three main areas: they possess expert knowledge relating to their bodies; they have the ability to make a diagnosis; and are capable of choosing a practitioner most suited to their health requirements. This paper details frustrations patients experience when their own knowledge is often ignored or discounted by health practitioners and promotes the idea that what we need for a more tolerant health environment is the ability to translate our ideas across a variety of expert discourses.
\end{abstract}

\section{INTRODUCTION}

Currently I am involved in research towards my doctoral thesis and this paper reflects an ongoing analysis of academic literature and interviews held with a variety of participant groups. The focus of my thesis relates to patients and practitioners who combine a variety of healing modalities and their ideas about responsibility, however, many of the terms used throughout this paper to describe health and healing modalities can invoke heated debate. This is especially pertinent to alternative and complementary therapies because there is no universal agreement about what in fact constitutes these practices. Therefore, for the sake of clarity within the context of this paper, the words 'orthodox' and 'biomedicine' refer to Western-style scientific medicine and 
these terms are used interchangeably throughout the text. As to defining what is meant by alternative and complementary medicines, I recognise this is a contentious matter, however I have chosen to use the definition provided by the 1987 New Zealand Department of Health Report which states that:

complementary therapies are those diagnostic and healing or health promoting techniques which are not usually offered within the western health care system (that is provided by statutorily registered 'health professionals' which include medical practitioners, nurses, physiotherapists, dentists, psychologists and chiropractors).

(Leibrich, Hicking and Pitt 1987:1)

CAM is an acronym for complementary and alternative medicine and I use this interchangeably with the terms alternative and complementary.

As previously noted, the interviews featured in this paper form part of the research towards my thesis. To date, interviews have been held with thirty respondents. These include in-depth face-to-face interviews with seven patients, eight CAM practitioners, and one orthodox medical-CAM practitioner. Telephone interviews have been held with five orthodox medical-cam practitioners. Two focus groups with general practitioners (GPs) have also been conducted. Patients were recruited through snowball sampling and practitioners by anecdotal information, Yellow Pages Directory and medical journal and popular media reports. The interviews lasted, on average, between one and two-and-a-half hours duration and followed a semi-structured format. Interviews were tape-recorded and, following transcription, coded using Atlas-ti software. Pseudonyms have been used throughout this paper when referring to patients and their interview responses in the text.

These interviews with patients who combine both orthodox and complementary and alternative medicines (CAM) reveal a complex range of ideas regarding expert knowledge within the medical and healing spheres. Much of this complexity involves perceptions of expertise - the kudos accompanying objective scientific knowledge on the one hand, and skepticism surrounding the empirical and subjective knowledge of lay individuals and many of the CAM modalities on the other hand. The development and privileging of orthodox medicine has been borne, in part, through an adherence to scientific paradigms at the expense of empirical knowledge, especially the knowledge and experiences of patients. This means that as medicine has become increasingly professionalised the value of lay knowledge has been eroded through 
the increasing power, status and authority of orthodox practitioners. My research reveals that patients, while acknowledging and wanting the benefits of biomedical knowledge, remain frustrated that much of this information appears out of their reach and their own experiences and expertise are given little credence. Concomitantly, resistance to biomedical hegemony exists, as demonstrated through the increasing use of CAM.

An important component of CAM is the value placed on the role of the individual, especially in relation to accepting responsibility for the healing process. Certainly the patients I interviewed believe they take responsibility for their health, manifested through their expertise in three main areas: knowing their own bodies; being able to diagnose; and using this knowledge to choose an appropriate health practitioner. Interestingly, these ideas about the primacy of the individual and personal responsibility are echoed in individualistic ideologies. Before discussing these understandings of expertise in detail I would like to provide some brief historical background to the development of biomedicine and CAM in New Zealand society in order to better locate contemporary practices and beliefs.

THE DEVELOPMENT OF BIOMEDICINE AND CAM IN NEW ZEALAND

Since early European colonisation of New Zealand a plurality of healing modalities has existed, including Western orthodox medicine, CAM, and traditional healing systems such as Ayurvedic, Chinese and rongoa Maori. However, despite this range of cultural influences the dominant modality remains the biomedical model.

In New Zealand, the early European settlers brought with them traces of the British health system which, although pluralist, privileged orthodox medicine. Another important factor transplanted here was the continued adherence to the individualistic ethos prevalent in Victorian society. In Britain, health care was predominantly the responsibility of families and individuals were not encouraged to seek the services of health practitioners or expect assistance from the state. However, this mode of health care proved unsustainable in New Zealand because of two main factors. First, New Zealand's economy was based around agricultural production and because of the size and geography of the country many people worked in sparsely populated and isolated areas (Hay 1989:5). Second, the early settlers were predominately single men hence there was an absence of families, especially females, to provide health care and advice (Hay 1989:32). This meant that people became reliant on doctors or healers when they were sick or injured. 
In Britain, the wealthy upper classes provided some charitable health care for the poor, however, migrants to New Zealand were mainly from the lower middle classes or upper working classes and as such were not in a position to fund private hospital care (Fraser 1984:56, Hay 1989:17). During the 180os doctors in New Zealand offered health care on a fee-for-service basis but for many people these costs were prohibitive. This meant that many found it difficult to access orthodox medical care; doctors were too expensive, and there was no public health system. This situation led to the formation of Friendly Societies. The Societies employed doctors, and financial members and their families could avail themselves of medical treatment through the payment of an annual subscription (Hay 1989:17, Wright-St Clair 1989:15).

The state gradually became involved in the provision of health care during the mid-18oos when Governor George Grey arranged for the establishment of public hospitals to treat both Maori and poor Europeans, although the latter were asked for some financial contribution towards their care (Fraser 1984: 56, Hay 1989: 18). This involvement transgressed the laissez-faire attitudes of the time, especially those relating to 'work, thrift, respectability and selfhelp' (Fraser 1984:54). Concern was raised in some quarters about how state intervention might interfere with the concept of individual responsibility and there was fear that this could result in a general public lacking qualities of self-reliance and becoming increasingly dependent upon the state to provide services such as health care (Sutch cited in Hay 1989: 19).

Despite these misgivings the state continued to increase its role within the health sector and its support of orthodox medicine was fundamental to the growth and dominance of the biomedical sector. Both private and public health services became more readily available and during the late 1800 s repeated attempts were made at securing government funding for hospitals and primary care. As New Zealand became urbanised the expanding labour-force became increasingly vociferous in their demands for an adequate health care system (Hay 1989:30). Technological advances together with the advent of a more professionalised medical work-force made hospitals an attractive place to seek medical treatment (Hay 1989:31-32). The Hospitals and Charitable Institutions Act of 1885 provided hospital funding through general taxation and local body rates, and people no longer considered treatment at public hospitals akin to seeking charity and consequently an increasing percentage of the population sought hospital-based care (Hay 1989:32). In 1900 The Public Health Act saw the creation of a Ministry of Health and a Department of Public Health which confirmed the increasingly dominant role of the state in New Zealand's health care system (Hay 1989: 42). This shift in government 
policy heralded changes that would become prevalent over the next few decades, especially those pertaining to responsibility. There was a gradual move away from ideologies espousing individualism to those reflecting a more collective ethos.

The most significant impact on the delivery of health care in New Zealand was the election of the first Labour government in 1935. Under the leadership of Michael Joseph Savage a social security system was introduced which promised assistance from 'the cradle to the grave' (Wright-St Clair 1989: 24). In 1938 the Social Security Act was passed, legislating universal provision for free mental and general hospital care, maternity services and general practitioner subsidies (Hay 1989:113). However, a protracted and determined campaign against government interference in the general practice arena was mounted by doctors and it was not until 1941 that the medical profession finally agreed to the implementation of a general medical services benefit (GMS), with the proviso that doctors could still charge patients a fee additional to the GMS if so desired (Hay 1989: 112-122).

Despite biomedicine gradually cementing its position as the predominant healing modality, alternative therapies were still widely practiced. During the 1800 doctors were not a cohesive profession and as Belgrave outlines, consisted of a mixture of 'itinerant street vendors, folk physicians and regular practitioners...[who] possessed no organization and no common medical knowledge' (1985:3-4). However, even if there was little homogeneity among orthodox practitioners they, along with druggists/chemists, were the only healers who possessed a distinct occupational status, with chemists also diagnosing and dispensing patent remedies (Belgrave 1985:289-90). Other occupational groups such as dentists, opticians, masseurs and public health officials emerged during the 1870 s and although not all doctors were resistant to the idea of alternative therapies, by the 1890 o a more pronounced demarcation between orthodox and alternative modalities was evident (Belgrave 1985:294, 304, 306). Practitioners such as herbalists, hydrotherapists, chiropractors and osteopaths were viewed as offering a different range of healing options compared to those offered by more orthodox systems, which included homoeopaths (Belgrave 1985:294). Homoeopathy was a popular alternative to orthodox medicine, although doctors discouraged its use by distancing themselves professionally from this group of health practitioners (Belgrave 1985: 299).

Three factors prevented alternative therapies from gaining equality with biomedicine. First, as scientific knowledge and technology became more widespread, orthodox medicine gained in status and popularity. Second, doctors 
transformed themselves into an increasingly homogenous and powerful profession and third, having to a large degree garnered support from the state, the medical profession attempted to limit the practice of alternative and complementary medicines (Dew 2003: 29). This in part occurred through legislation marginalising alternative medicine, for example the Tohunga Suppression Act 1907 and the Quackery Prevention Act 1908. However, despite these obstacles, CAM is now a growth industry both in New Zealand and in many other Western-style societies.

In the twenty-first century CAM has certainly established a niche market in New Zealand and health services offered to the public these days are pluralist in nature, sometimes combining aspects from both orthodox and CAM modalities (Fulder 1996:3). For example, one CAM practitioner I spoke with illustrated this point by saying:

Often people who come into the shop don't have a GP and they need to have one so I will refer them to GPs who refer people to us because I know they're not going to get a hard time about using natural therapies.

(Female herbalist)

A biomedical doctor interviewed stated his reasons for utilising both orthodox and CAM therapies within his practice:

I found that my training and the drugs available did not cope with the kinds of things that were coming through so naturally you reach out for other possibilities...I think I was one of the first GPs in this area who did acupuncture and I was one of the first batch of GPs in this area who did manipulation with medicine... [in our clinic] we had massage, psychology, counselling, acupuncture, a herbalist, an osteopath, physiotherapists...we had all those paradigms working under one roof, working together.

(Male GP/CAm practitioner)

In New Zealand today there is a burgeoning CAM industry which offers consumers a smorgasbord of health care options incorporating therapies such as radionic and psionic medicine, colour therapy, herbal medicine, naturopathy, homoeopathy and Bach flower remedies through to practices involving spiritual surgery or attendance at New Age awareness weekend retreats. Orthodox 
medicine, on the other hand, involves treating patients at primary (general practitioners, nurses, physiotherapists, dentists and so on), secondary (medical specialists) and tertiary (hospital) levels.

According to the Ministerial Advisory Committee on Complementary and Alternative Health (MACCAH) there are at least seventy CAM modalities available in New Zealand at the present time (MAACH 2002: 15). CAM products can also be purchased from a variety of outlets such as health food shops, supermarkets, chemists, CAM practitioners (such as herbalists or naturopaths) and also by using the internet or mail order catalogues (MAACH 2003:2).

Patients interviewed for this research project reflect the above findings, combining orthodox medicine with a wide variety of cam therapies. For example, one respondent (a male in his late 6os), has over the past twenty years used Buteyko ${ }^{1}$, naturopathy, acupuncture, Chinese herbal medicine and electrotherapy in order to treat a variety of health problems. He also continues to consult orthodox health practitioners. A woman (in her mid 30s) who suffers continual back pain has attended neurologists and orthopaedic surgeons as well as undergoing CAM procedures such as a rhizotomy ${ }^{2}$, acupuncture and osteopathy. She has also visited a colour therapist for other health problems.

As can be seen there is a diverse range of CAM therapies available to consumers and currently, under common law, all modalities are permitted to practice in New Zealand. However, with the recent advent of the Health Practitioners' Competence Assurance (HPCA) Bill and impending recommendations from MACCAH, it is envisaged this situation will change. For instance, osteopaths became a statutorily registered profession in September 2004 and other CAM practitioners I spoke with, such as herbalists, expressed an interest in being incorporated under a statutory umbrella.

However, even though CAM is increasing its share in the healing market-place, it still faces opposition from orthodox practitioners (see Hadlow 1989) and questioning about its efficacy and place in the New Zealand health system (Beaven 1989, Cole and St George 1993). Much of the friction between orthodox medicine and CAM relates to debate surrounding the legitimacy of science over the legitimacy of clinical practice (Willis 1994:64) and an excellent illustration of this is evident in the well-publicised case of the Medical Practitioners Disciplinary Tribunal's findings against Dr Richard Gorringe. According to the Health and Disability Commissioner, 'a registered medical practitioner cannot discharge his or her responsibility to treat patients appropriately simply by claiming the particular treatment was 'alternative' or 'complementary" 
(NZGP 2003:10). The tribunal was especially concerned at Dr Gorringe's use of a procedure called peak muscle resistance testing and found that it was 'not a plausible, reliable or scientific technique for making medical decisions. It was unacceptable and irresponsible of Dr Gorringe to rely on muscle testing to the exclusion of conventional diagnostic methods' (NZGP 2003:10 my emphasis). It is this reference to scientific knowledge that has had considerable influence on biomedicine's ability to dominate the health care sector and maintain influence over the validity of CAM and lay knowledge.

THE ROLE OF SCIENCE AND TECHNOLOGY

Challenges to the orthodox medical model are evident because people are demanding a choice of health care options incorporating both CAM and orthodox modalities. However, as previously mentioned, the current status of biomedicine compared to CAM is largely due to the privileging of scientific and technological knowledge over the more metaphysical philosophies underpinning many CAM therapies, for example the importance of the mind, body and spirit as a single entity together with an individual's relationships with both the self and society (see Fulder 1996:4-7 for a detailed description of these philosophies). The growth of scientific knowledge and its impact on the biomedical model is briefly outlined as follows.

During the nineteenth century knowledge about the human body expanded because of a range of scientific discoveries and technological advances. For example, laboratory research techniques were refined enabling the exploration of body tissues and as a result knowledge was gained about matters relating to respiration, nutrition, the digestive system and endocrinology. With discoveries by Louis Pasteur (1860) and Robert Koch, an understanding of infectious diseases was made and new cures developed. The use of antiseptics greatly advanced operating room conditions and improved anaesthetics significantly enhanced surgical outcomes. Public health regulations also came into force.

In the twentieth century technological discoveries have seen the advent of $\mathrm{x}$-rays, computed tomography (CT), and magnetic resonance imaging (MRI). This has aided in the detection of diseases and the possibility of surgical or chemical intervention. Pharmacology has been revolutionised with the advent of antibiotics. In the 1920 insulin treatment for diabetes became available; in 1977 small-pox was eradicated, and during the same decade the first heart transplant surgery took place. Such was the confidence of orthodox medicine that in 1969 the US Surgeon General, Dr William Stewart, announced that 
infectious diseases were a thing of the past. However, such extolling of the virtues of biomedicine has its critics. Illich argues that biomedicine and its practitioners should not be credited with the 'elimination of old forms of mortality and morbidity' (2001:265) because there is considerable evidence to support the premise that it was the improving living standards in many Western-style societies during the eighteenth and nineteenth centuries that was responsible for diminishing rates of infectious diseases as opposed to the use of vaccines and antibiotics (McKeown 1998:71-74; Tesh 1988:38). And it is important to note that diseases such as polio, yellow fever, plague, cholera and typhus are still prevalent in many poorer countries today (Tesh 1988: 69).

As technological and pharmacological advances have been made, medicine has become more specialised and secondary and tertiary services commonplace. Modern technology in the guise of the stethoscope, $\mathrm{x}$-rays, laboratory findings, CT and MRI scans means knowledge about the body is no longer predominantly the domain of the patient because others now have access to information that is often internal and unavailable to the person concerned (Foucault 1973). By the turn of the twentieth century, patients' views concerning their bodies and ill health were often discounted because the 'responsibility for discovering and labeling illness had become the preserve of the medical practitioner' (Lupton 1994:86). Knowledge about health and illness also led to theories concerning the medicalisation of society together with concepts relating to the construction and surveillance of the body and the way social problems have come under a medical gaze and control (see Annandale 1998, Foucault 1973, Nelkin and Tancredi 1989). An example of this is the prescribing of Ritalin for children diagnosed with Attention Deficit Disorder (ADHD), anti-depressants given for a broad spectrum of psychiatric conditions and drugs such as Viagra or Cialis promising a life-time of sexual activity. The role of pharmaceutical companies and their marketing strategies in relation to the medicalisation of social problems also needs to be noted here (Singer and Baer 1995).

So-called scientific and technological advances have also raised questions about iatrogenics or doctor-made diseases. For example Illich contends that 'technical medical intervention' inflicts considerable anguish and suffering on populations because patients suffer complications from medications and surgical procedures (2001: 266-267).

Despite concerns about the medicalisation of society and iatrogenic disease, generally, in Western-style societies, people enjoy better health compared to their forebears and, because of this, members of the medical profession con- 
tinue to be valorised for their scientific and technological prowess and are still accorded high social status (Lupton 1994: 84). This status is a major factor in the gap that remains between lay patients and their 'subjective' knowledge and the orthodox practitioner armed with 'objective' scientific knowledge.

Although scientific and technological advances have been major contributors to the dominant position biomedicine has gained in Western-style societies, notwithstanding, alternative and complementary therapies have also maintained and increased their presence. Why has this situation occurred?

I believe one of the factors causing this change has been an increasing emphasis on individualism in both social and political spheres. In this context individualism promotes liberty and freedom of choice for individuals and a distancing from collective interests and demands. Within an individualistic environment individuals become solely responsible for the decisions they make and they cannot hold the State or other individuals accountable for their actions. One of the ramifications of individualsm has been a questioning of authority and the role of 'experts' and 'professionals' and this attitude profoundly affects attitudes about health, illness and responsibility. CAM therapies promote the individual as a major force in the healing process:

The healer clearly cannot have the kind of authority exercised by the conventional science-informed doctor, the person who draws on an established body of knowledge...it seems that the healer must - crucially - be the patient.

(Heelas 1996: 82-83)

Much of the debate between lay and expert knowledge concerns the values of subjectivity and objectivity. Scientific knowledge is largely viewed as being objective and support for this paradigm within the health sector continues unabated. As Glymour and Stalker (1989:21) boldly state:

Medicine in industrialized nations is scientific medicine. The claim tacitly made by...physicians, and tacitly relied on by their patients, is that their palliatives and procedures have been shown by science to be effective. Although the physician's medical practice is not itself science, it is based on science and on training that is supposed to teach physicians to apply scientific knowledge to people in a rational way. 
This view is somewhat tempered by those who work within the biomedical sphere. For instance a seventh year surgical registrar muses:

The thing that still startles me is how fundamentally human an endeavor it [medicine] is. Usually, when we think about medicine and its remarkable abilities, what comes to mind is the science and all it has given us to fight sickness and misery: the tests, the machines, the drugs, the procedures. And without question, these are at the center of virtually everything medicine achieves. But we rarely see how it all virtually works. You have a cough that won't go away - and then? It's not science you call upon but a doctor. A doctor with good days and bad days. A doctor with a weird laugh and a bad haircut. A doctor with three other patients to see and, inevitably, gaps in what he knows and skills he's still trying to learn.

(Gawande 2002: 4-5)

And further, in a local context, Robin Kelly, a New Zealand GP who now concentrates on mind-body healing, believes:

Medical technology will not answer all our health problems. It will, I am sure, do much that is wonderful. Keyhole surgery and designer drugs will continue to help us 'get a life' - we will recover more quickly from medical and surgical procedures and have fewer side effects. The cautious use of molecular engineering techniques, will, with the right intent, ease suffering, and save lives... But for many this will not be enough. For these people, healing answers will not be found in chemical laboratories or operating theatres... answers will be found in society, in loving relationships, in their own past and hopefully in their own futures. They will be helped by health professionals who understand their own roles, their strengths and their limitations, who match their skills with compassion, their knowledge with humanity. Professionals who take time to guide and listen before prescribing and operating, professionals who allow patients the freedom to heal.

(Kelly 2000: 208)

The components of art and science within the biomedical paradigm remain precariously balanced. As Gordon (1988) describes, there has been (and still is) a move to introduce more 'science' into biomedicine. The reasons for this 
are multifarious: there is a desire to minimise the 'uncertainty' and 'risk' implicit in medical encounters; to placate increasing demands for medical accountability; and both medical practitioners and lay individuals are becoming increasingly reliant on the use of digital computers to provide information and answers to health problems (Gordon 1988:262). Gordon argues that by privileging the scientific encounter a preference for 'formal' knowledge is evidenced as opposed to knowledge systems reflecting 'practical knowledge' which is derived from clinical experience encompassing the 'senses of sight, sound, touch, smell, as well as emotions and more general senses, such as...a gut feeling' (Gordon 1988:269).

While this humanistic approach alerts us to the 'art' as opposed to the 'science' in medicine, the subjective perspective as opposed to the objective, critics of empirical evidence such as Karl Popper strongly support and advocate scientific knowledge. Scientific knowledge is based on an objective perspective - a theory is proposed, exhaustively tested, and either proved or eliminated. This way knowledge progresses or is achieved (Popper 1994:13). Scientific theories achieve their status by 'falsifiability, or refutability, or testability' (Popper 1972:37). Popper argues that the theoretical underpinnings of disciplines such as psychology (as described by Freud) and Marx's view of history are found wanting because 'it is easy to obtain confirmations, or verifications, for nearly every theory - if we look for confirmations' (1972:36). Popper maintains he is not disputing the importance of psychological or historical interpretations, but he believes they cannot be viewed as scientific. While Popper accepts that empirical evidence is an important component of scientific endeavour, he argues it has to be backed by rigorous testing as opposed to mere observation (1972:38). And it is the reliance on empirical evidence that is often central to arguments by the biomedical community towards CAM and lay knowledge.

Criticism of CAM focuses on two main areas. First, the unproven nature of many therapies and second, many of the remedies and preparations used do not face the same rigorous testing that biomedical medications undergo (Furnham and Forey 1994:459), Radner and Radner 1989:151, Saunders 1996: 108-113, Willis 1994:64-69). CAM proponents counter this argument by stating that the methods and results used and obtained by CAM therapies are not testable within the framework of conventional medicine because treatment is based on a case-by-case basis (Fulder 1996: 9, Furnham and Forey 1994: 459, Saunders 1996:111-113).

As Willis (1994:64) adroitly surmises, biomedical opposition to CAM is premised on the lack of scientific evidence to support the 'paradigms of knowledge 
that these practitioners use. CAM treatments are based on knowledge gained from 'anecdotes, testimonials and single case studies' (Willis 1994: 65). Biomedical knowledge, on the other hand, is formed through scientific methodology: double-blind randomised trials, replication of tests, peer reviews and the publishing of results in professional journals (Willis 1994: 65). This methodology embraces Popper's doctrine of falsifiability, refutability and testability.

However Willis (1994:62) makes the point that many CAM practitioners incorporate some scientific or medical techniques into their repertoire of diagnostic practices, such as taking a full history or blood pressure readings. I found evidence of this during my research. For example, a homoeopath I talked to reported that he took a comprehensive history from a client:

For an adult I'd sit down for a whole hour and get them to talk about their symptoms as well as their past health history, their family history and then I'd look at what the symptoms were, what is the body showing me, why is the person feeling this way?

A herbalist told me that she

...looks at the tongue, looks at medical tests. Sometimes I ask for medical tests to be done, a whole combination of things.

She also made the point that 'sometimes all the medical tests in the world won't tell you what's wrong.

Another herbalist said she used the following techniques to help make a diagnosis:

Mostly we talk. People will tell you what's going on with them. I do iridology as well and if I need to I do a physical examination like listen with a stethoscope, measure blood pressure, listen to the chest, feel around their gut if there's something wrong, just fairly basic because I haven't had extensive medical training. But I can feel if there's something different.

While it would be incorrect to see the 'flight from science' towards CAM as a wholesale rejection of orthodox medicine, there is an argument that dissatisfaction with biomedicine's preoccupation with scientific and technological expertise has been caused because of our inability to use this type of knowledge wisely (Hawkins 1999:6). As Gawande (2002:116) remarks, doctors 'be- 
lieve the world to be decipherable and logical, [and they deal] with problems we can see or feel or at least measure with some machine. However, if doctors are confronted with problems they cannot account for then the profession is often 'dismissive... we're apt to conclude [it's] all in the [patient's] head' (Gawande 2002: 116).

In her excellent account of patients and caregivers experiences of ill health, Hawkins states that patients who turn to CAM do so as a reaction against 'perceived inadequacies in the current biomedical model...[they turn to CAM because of ] disillusionment, frustration, or anger at orthodox medicine' (Hawkins 1999: 125). She goes on to say:

...the many forms of alternative medicine are characterized by what orthodox medicine is not. If the model of patient-hood in biomedicine is one of passivity, in alternative medicine the model is one of agency - the patient is expected to be a fully involved participant in his or her own therapy. If in biomedicine specific treatments are verified by statistical evidence, in alternative medicine verification is arrived at by anecdotal evidence - the fact that a given therapy has worked for some people. In biomedicine, it is the disease that often seems to be the focus; in alternative medicine, the individual with the disease. Biomedicine is allied with technology; alternative medicine is associated with natural agents and processes.

(Hawkins 1999: 126)

CAM supports the self-healing capacities of the body, aligning itself with 'natural' remedies and the power of positive thought. The values of 'self-reliance, individualism, and perhaps most important, activism' (Hawkins 1999:129) illustrate a move away from scientific and technological expertise and explanation for illness to one where individuals develop an explanatory model that makes sense to them. Orthodox medicine tries to make sense of ill health from an etiological point of view: what is the disease or illness which a person has, what are its origins, what can be done about it and so on. However, lay perspectives are concerned not only with the reasons why disease has occurred but also the experience related to illness (Lupton 1994:79, Williams and Popay 1994:123). Patients often feel the biomedical approach does not address or adequately answer their concerns. One of the phrases repeated to me constantly during my interviews with patients was that 'doctors only treat symptoms not causes'. Put simply, patients and their families want to know why things happen to them. One research participant (a semi-retired man in 
his 6os) expressed such a sentiment when talking about his cancer, an osteosarcoma affecting his leg resulting in its amputation. Jack said:

I'm mystified as to why, for example, one gets cancer. Why does one get cancer in the leg? In the bone? I really think it was caused by an injury but no-one else seems to think that. I got a big thorn in it about 20 years ago, it hit the bone, the thorn hit the bone and I was laid up for a couple of weeks afterwards. But then it gradually came right and I carried on, but it seemed too much of a coincidence to me that it, the sarcoma, came up in exactly that spot. The doctors don't seem to think it was relevant.

The focus on scientific explanations of illness has replaced patients' own interpretations of what is happening to them and they feel increasingly detached from the process that is meant to help them. As illustrated above, expert medical opinion could not provide Jack a reason for his cancer therefore he developed his own theory.

While the debate about CAM versus orthodox medicine can be divided into arguments about subjectivity or objectivity, or the value of lay as compared to expert knowledge, or art over science, I believe that to reduce this complex matter into such binaries is simplistic and unhelpful. As Micozzi (1996:3) states:

Some of the central ideas of biomedicine are very powerful, but are becoming intellectually stale. The study of dead tissue cells, components and chemicals to understand life processes, and the quest for 'magic bullets' to combat disease are based upon a reductionist, materialist view of health and healing. We have made tremendous advances over the past hundred years by applying these concepts to medicine. However, the resulting biomedical system is not always able to account for and use many observations in the realms of clinical and personal experience, natural law, and human spirituality.

The scientific community argue they are the rightful arbiters of what can and cannot be either included or excluded from a scientific paradigm (Pickering 2004: 167). However, Pickering makes the point that evidence based medicine (ЕВM) utilising randomised clinical trials (RСT) is not a completely objective or neutral process. Clinical trials testing for a single variable may include the choice of a 'wrong sort' of variable or ignore variables that are perceived as 'non-scientific', such as patients being able to talk to someone about their ill- 
ness (Pickering 2004: 174). In other words, RCTs are a value-laden process that can be seen as subjective. Pickering believes that scientific endeavour has to be placed within a social context and ultimately both biomedicine and CAM will have to be subjected to some form of testing. However the methods used will need to encompass a framework that takes into account the plurality of therapies and their varied ideological base.

While some supporters of individualism may express dismay at a challenge being mounted to the privileging of rationalism and science, free choice is a central tenet of this ideology. To this end a health sector offering a range of healing modalities incorporating lay and professional expertise can be seen as adhering to individualistic ideologies.

\section{INDIVIDUALISM AND THE EXPERT PATIENT}

The desire for knowledge about health and illness was evident among my respondents: all of them talked about researching their health problems using a variety of tools - the internet, libraries, hand-outs from practitioners, discussion groups and so on. Knowledge is central to ideas about expertise and, within the realms of health and illness, can be located in three main categories: personal experience (subjective), public information (a mix of the subjective and objective), and established knowledge (objective) (Chick 1992:35-37).

My research revealed that there is a constant tension between knowledge considered expert or lay and this is largely based on whether the information has been derived from subjective or objective sources. In the following section I discuss the sites of patients' self-described expertise: their bodies, diagnosis, and which practitioner best suited their health requirements.

\section{THE BODY}

Challenges to the delivery of health care have raised questions about expertise - who knows the body? the patient or the practitioner? The focus on scientific explanations of illness has replaced patients' own interpretations of what is happening to them and they feel increasingly detached from the process that is meant to help them. However, as outlined above, many people today are prepared to question the expertise of health professionals. In regard to expert knowledge about the body, one of my participants said:

I really would like them [medical doctors] to treat me as though I have some knowledge of my own body and, in that sense, I'm the 
expert of knowing my body, and talk to me in a way that doesn't undermine my intelligence and doesn't think that, well, medical information is too hard for people to understand because it's not.

(Genevieve, late 3os, tertiary student)

Another participant expressed the following viewpoint:

It's a feeling of doctors know best and they don't...we know our own bodies.

(Fay, 3os, part-time student/gardener)

Fay also recounted how she had consulted a doctor because she thought she was pregnant. The test results indicated this was not the case and she felt the doctor displayed a patronising attitude towards her because of her lack of expertise in knowing what was happening to her own body. When she returned a week later further tests confirmed her belief that she was indeed pregnant and she expressed anger that the doctor had not accepted her original diagnosis. She reported that as a result of some of her experiences she has realised: 'I am in control of my body and I can make decisions...informed decisions'. However, Fay also recognised the dilemma that faced her when she did not have adequate knowledge and she commented thus about doctors:

I have to put my faith in them because I don't know enough to know if it's right so I suppose... they have the responsibility to ensure that I'll be okay and they give the best possible care and advice.

Patients questioned the expert knowledge of some practitioners. They wanted to be treated, as one participant remarked, 'as if you've got a brain in your head'. Another participant (Elizabeth, an administrator in her 30s) described how she suffered from a relatively uncommon musculoskeletal condition and was dismayed at the treatment she received from an osteopath. She believed she knew much more about her condition than practitioners in general and wanted them to admit when they are not able to help and refer on to someone who may be able to assist. Elizabeth also thought being a medical doctor only meant a person had the potential to be knowledgeable, but this did not equate to actually possessing the required expertise.

Patients often express contradictory beliefs: they possess expert knowledge about their bodies but also expect expertise about that same body from health 
professionals. However, patients have quite different expectations with regard to the expert knowledge of practitioners and a higher, more accountable standard is demanded from medical doctors as opposed to CAM therapists.

\section{DIAGNOSIS}

When people feel unwell they generally search for an explanation. The biomedical model 'explains sickness in terms of pathophysiology - abnormal structure and function of tissues and organs' (Weston and Brown 1989:79). However Weston and Brown (1989) argue that patients do not view ill health in terms of sickness, but instead in terms of personal experience which is construed as illness. In other words, 'many people can have the same disease, but the illness experiences of each person are unique' (Weston and Brown 1989:79). In light of these subjective experiences of ill health, lay people develop explanatory models for themselves combining a range of information gleamed from, for example, the electronic mass media, 'home doctor' books, novels, medical advice columns found in magazines, personal experience and discussions with other people. All my respondents described talking to other lay people, usually friends and family, about physical symptoms. Armed with knowledge from a variety of sources patients then felt able to make a diagnosis. For instance, Genevieve said:

...when I have a health problem what I do is really becoming as educated as possible myself on what the issue is and what I think might lead to a good pathway for dealing with the health problem.

Stevie, a nurse in her 50s, expressed the opinion that she knew her body well enough to be able to decide what medications she should take:

I want to be able to say I take Gingko because I believe it will help my memory and I don't want them [doctors] to tell me, no you're not going to take that.

Fay recounted how she felt a bit 'down' and diagnosed depression which she believed was due to 'my situation at the time'. She also talked about living in Australia where her son was bitten by a spider:

...I saw two marks you know, like fang marks from a spider... and the way he was reacting it was just like something real bad [but by the time they got to the hospital the marks had disappeared] and doctors don't believe what you are saying, what you know... [they said] 
Kiwis are so paranoid about spiders.... and I felt really silly.

This patient was extremely upset and disappointed that medical staff at the hospital had not agreed with her diagnosis and had felt humiliated in the process.

Sarah (a former teacher in her 40 os who is currently completing her undergraduate degree) explained diagnosis in the following terms; if she thinks she needs a blood test then she consults a doctor, however if she perceives her problem to be nutritional in origin, then she consults a CAM therapist of some kind. Consultations with CAM practitioners are preferred, according to this participant, because she receives 'a more negotiated answer to a problem'.

All participants described making diagnoses but also expressed contradictory statements in regard to their expectations of health practitioners when it came to their diagnostic skills. For instance, when visiting an orthodox practitioner Genevieve said:

I guess the things you ask for is a diagnosis and tests and things like that.

However, she felt that when attending a CAM practitioner a diagnosis:

....is not always necessary...because I've had so many different diagnoses by natural health practitioners that you could say that doesn't make any sense...but the thing is that's not the emphasis...it's on what's going to work to make you feel better and I generally find the diagnosis can be quite unimportant...

Genevieve described the security in knowing that she had been to a doctor and received a diagnosis of gluten intolerance but said, 'for myself I don't actually need that diagnosis any more'.

As illustrated by these examples expertise in diagnosis can be problematic. Some participants admitted to being 'surprised' by a diagnosis they had received, indicating there are discrepancies between what they perceive to be the cause of their ill health and the views of practitioners. Patients appear very unforgiving of orthodox medicine if a misdiagnosis is made or treatment is not to their liking, however the same cannot be said concerning the relationship with CAM which is usually described in a more positive light, and often because of the perceived holistic approach adopted by practitioners. Patients 
are not unduly concerned if CAM practitioners do not make a diagnosis or treatment is unsuccessful. What is revealed through my present research is that patients often believe they know what is ailing them and it is this expert knowledge which underpins their choice of health practitioner if intervention is required.

WHICH HEALTH PRACTITIONER TO ATTEND

The patients I interviewed have described how they self-diagnose and use this knowledge to choose a health practitioner. However, most literature on this subject suggests that in fact the majority of patients initially consult orthodox medical practitioners before turning to CAM therapies (Sharma 1996: 235). Orthodox medicine is first in the 'hierarchy of resort' after home-based remedies have been tried, and it is usually only after patients become disgruntled or disenchanted with conventional treatments, for a variety of reasons, they search for alternative modalities (Sharma 1996:235).

The choice of health practitioner is reached in very much the same way as making a diagnosis - knowledge is gained from a variety of sources; visual and print media, the internet, talking to friends and family. For instance, Genevieve noted:

I choose particular natural health practitioners for particular specific ailments and I wouldn't see one health practitioner as being able to treat every ailment.

She went on to suggest another important component when choosing a practitioner involved is:

...talking to other people who maybe have similar health issues and asking what they did and that's why it's really important to have networks of people with similar issues...getting to know a group of people who have coped with these things.

Jack has visited a wide variety of alternative practitioners over the last 20-30 years. His main reason for moving away from conventional medicine was his dislike of what he termed 'strong medications'. However, he also alludes to the dilemma of being torn between experts since diagnosed with cancer:

...when the tumor starts to grow I'm too scared not to have it surgically attended to because I can't think of any other way...I wasn't in a position to argue. 
Jack preferred the non-invasive treatments offered by CAM practitioners but said he would not be happy to attend one because of the type of cancer he had. However, he did attend a complementary therapist for palliative care after surgery. Phyllis (a retired but extremely busy widow in her 7os) described white spots on her fingernails and diagnosed a zinc deficiency, and then seeking out 'someone who's into herbal medicine or minerals and vitamins [and] then you get a prescription of what you need to take for the symptoms that you're showing?'

All patients I talked with 'shop' around when choosing practitioners, and appear certain of which modality to choose depending upon the perceived diagnosis - whether it was a nutritional problem, sinus or more of a psychosocial nature. Orthodox practitioners are consulted for conditions labeled serious or acute and CAM therapists are often visited for chronic conditions. Patients question the expert knowledge of practitioners, both biomedical and complementary, and compare their own knowledge with the apparent expertise of health professionals. The subjectivity of the lay person's experience is often discounted or ignored by those who work within the orthodox environment and this is one of the factors pertinent to a burgeoning complementary therapy sector. However, it is important to note that patients also describe significant expectations of the biomedical model, especially when dealing with 'serious' health problems, such as cancer. These conflicting beliefs produce a tension between wanting and resenting medical expertise.

\section{DISCUSSION}

In this paper I have described an array of ideas surrounding the notion of expert knowledge within medical and healing encounters. Expertise is a multi-layered concept. For example one layer reveals the biomedical world and its reliance on an objective scientific paradigm. Another layer illustrates the subjectivity behind so-called scientific objectivity (Pickering 2004). Medical practitioners describe yet another view of expert knowledge, embracing both objective and subjective paradigms that have been formulated through clinical intuition and scientific knowledge. CAM practitioners offer a different view of expertise based on their training, which at times incorporates scientific knowledge, as well as their empirical knowledge. However the focus of this paper has concentrated on patients' views of expertise and again a multi-layered landscape of ideas has revealed expertise in knowing their bodies, making a diagnosis and using this knowledge to consult a practitioner most suited to their needs. 
One of the central tenets of CAM is that of self-responsibility where patients are encouraged to become their own 'doctor' and acquire expertise about their own bodies. Certainly the patients I interviewed do not see themselves as mere recipients of expert knowledge and are quite prepared to challenge and question the skills of orthodox practitioners, and on occasions, CAM therapists. However, my research indicates that patients appear somewhat ambivalent about CAM and its knowledge base and demonstrate low expectations towards many therapies. I believe that one of the reasons for this ambivalence is the continued privileging of scientific paradigms, and while patients may acknowledge a preference for treatments that offer a more metaphysical component, when they require 'answers' to health problems, they remain reliant on the science and technology provided by the biomedical model.

The ramifications of this palimpsest of expertise are profound. Individualism, as the dominant New Zealand European experience of personhood, promotes the primacy of the individual and by inference, their expertise. However, I believe it is possible that some patients may develop an unjustifiable confidence in their healing expertise. Certainly the patients I interviewed indicate that at times ideas they have concerning the state of their health are at considerable variance to the views of health practitioners. I believe that through the notion of self-responsibility and the idea that every person can be 'their own doctor' biomedical expertise is now being undervalued. Conversely, by paying scant attention to the expertise of patients, medical practitioners lose not only a valuable diagnostic tool but also the ability to communicate in a more meaningful way. Their frequent privileging of biomedicine over CAM removes a worldview that is central to many people's ideas of health and illness because it embraces the social, cultural and biological aspects of their lives.

Anne Scott (2003) draws attention to biomedicine's view of the body-as-object and the attempts by CAM practitioners to collapse the dualistic notion of a biological world on the one hand and a social and cultural world on the other. In order that the complexity of patients and practitioners views are revealed and understood it is important that ideas and beliefs about health and illness and healing modalities are viewed from a wide range of perspectives and not just at a subjective or objective level. As Scott states, 'the world is subdivided into boundaries which are differentially permeable to information, while information takes different forms within different systems' (2003:303). Therefore, she contends, we need to find a way to translate these different discourses; we need 'communication across difference' (2003:303).

The difference I have described in this paper lies in the multiple discourses 
we have of expert knowledge. What we need is a way to translate these views of expertise across a variety of healing encounters such as patient-doctor, patient-CAM practitioner, orthodoX-CAM practitioners, and biomedicine-CAM paradigms. By communicating about the different layers of expertise, a translation could effect a more tolerant and appreciative environment concerning the multiple levels of expertise. This in turn, I believe, would improve the quality of many people's experiences of health and illness, whether they are patients or health practitioners.

\section{ACKNOWLEDGEMENTS}

I would like to thank Ruth Fitzgerald for her extremely helpful comments on earlier drafts of this paper.

NOTES

1 A special breathing technique devised by Professor Konstantin Buteyko to control the way asthmatics over-breathe.

2 According to Dorland's Medical Dictionary this procedure involves: 'Interruption of roots of spinal nerves within the spinal canal... [carried out for] relief of essential hypertension... relief of intractable pain' (p.1188).

\section{REFERENCES}

Annandale, E. 1998 The Sociology of Health and Medicine: A Critical Introduction, Cambridge: Polity Press.

Beaven, D.W. 1989 'Alternative medicine a cruel hoax - your money and your life?', New Zealand Medical Journal 102: 416-7.

Belgrave, M. 1985 'Medical Men' and 'Lady Doctors': The making of a New Zealand profession, 1867-1941. Unpublished $\mathrm{PhD}$ thesis. Wellington: Victoria University of Wellington.

Chick, N. 1992 'Being Healthy: Measuring a Construct' in J. Boddy and V. Rice (eds) Health Perspectives and Practices, Palmerston North: Dumore Press: 29-47.

Cole, D. and St George, I. 1993 'Medicine at the fringes', New Zealand Medical Journal, 106: 130-3. 
Dew, K. 2003 Borderland Practices, Dunedin: University of Otago Press.

Foucault, M. 1973 The Birth of the Clinic: An Archaeology of Medical Perception, London: Tavistock Publications.

Fraser, G. 1984 'An Examination of Factors in the Development of New Zealand's Health System', in I. Shirley (ed) In the Public Interest: Health, Work and Housing in New Zealand, Auckland: Benton Ross: 53-75.

Fulder, S. 1996 The Handbook of Alternative and Complementary Medicine, Oxford: Oxford University Press.

Furnham, A. and Forey, J. 1994 'The Attitudes, Behaviours and Beliefs of Patients of Conventional vs Complementary (Alternative) Medicine', Journal of Clinical Psychology, 50:458-69.

Gawande, A. 2002 Complications: A Surgeon's Notes on an Imperfect Science, New York: Picador.

Glymour, C. and Stalker, D. 1989 'Engineers, Cranks, Physicians, Magicians', in C. Glymour and D. Stalker (eds) Examining Holistic Medicine, New York: Prometheus Books: 21-8.

Gordon, D.R. 1988 'Clinical Science And Clinical Expertise: Changing Boundaries Between Art And Science In Medicine', in M. Lock and D.R. Gordon (eds) Biomedicine Examined, Dordrecht: Kluwer Academic Publishers: 257-295.

Hadlow, V. 1989 'Alternative Medicine’, New Zealand Medical Journal, 102: 21.

Hawkins, A.H, 1999 Reconstructing Illness: Studies in Pathography, Indiana: Purdue University Press.

Hay, I. 1989 The Caring Commodity: The Provision of Health Care in New Zealand, Auckland: Oxford University Press.

Heelas, P. 1996 The New Age Movement: The Celebration of the Self and the Sacrilization of Modernity, Oxford: Blackwell Publishers Ltd.

Illich, I. 2001 'The epidemics of modern medicine', in B. Davey, A. Gray and C. Seale (eds) Health and Disease: A Reader ( $3^{\text {rd }}$ ed), Buckingham: Open University Press: 264-269. 
Kelly, R. 2000 Healing Ways: a doctor's guide to healing, Albany: Penguin Books.

Leibrich, J., Hickling, J. and Pitt, G. 1987 In Search of Well-Being: Exploratory Research into Complementary Therapies, Wellington: Health Services Research and Development Unit, Department of Health.

Lupton, D. 1994 Medicine as Culture, London: Sage Publications.

McKeown, T. 1998 'Determinants of Health', in P.J. Brown (ed) Understanding and Applying Medical Anthropology, California: Mayfield Publishing Company: 70-76.

Micozzi, M. 1996 Fundamentals of Complementary and Alternative Medicine, New York: Churchill Livingstone.

MAACH (Ministerial Advisory Committee on Complementary and Alternative Health) 2002 Terminology in Complementary and Alternative Health, Wellington: Ministry of Health: 1-20.

MAACH (Ministerial Advisory Committee on Complementary and Alternative Health) 2003 CAM consumers, Wellington: Ministry of Health.

http://www.newhealth.govt.nz/maccah/providers.htm (Item sourced 10.12.2003)

Nelkin, D. and Tancredi, L. 1989 Dangerous Diagnostics. The Social Power of Biological Information, usA: BasicBooks.

NZGP (New Zealand General Practitioner) 200317 September, page 10.

Pickering, N. 2004 'The Quantum Booster and medical orthodoxy', in K. Dew and R. Fitzgerald (eds) Challenging Science: Issues for New Zealand Society in the $21^{\text {st }}$ Century, Palmerston North: Dunmore Press: 167-186.

Popper, K. 1972 Conjectures and Refutations: The Growth of Scientific Knowledge, London: Routledge and Kegan Paul.

Popper, K. 1994 Knowledge and the Body-Mind Problem: In defence of interaction, London: Routledge.

Radner, D. and Radner, M. 1989 'Holistic Methodology and Pseudoscience', in C. Glymour and D. Stalker (eds) Examining Holistic Medicine, New York: Prometheus Books: 149-159. 
Saunders, J. 1996 'Alternative, complementary, holistic..., in H. Upton (ed) Philosophical Problems in Health Care, Aldershot: Avebury.

Scott, A. 2003 'A metaphysics for alternative medicine: 'Translating' the social and biological worlds', in S.J. Williams, L. Birke and G. Bendelow (eds) Debating Biology: Sociological reflections on health, medicine and society, London: Routledge: 298-310.

Sharma, U. 1992 Complementary Medicine Today: Practitioners and Patients, London: Routledge.

Sharma, U. 1996 'Using Complementary Therapies: A Challenge to Orthodox Medicine?', in S.J. Williams and M. Calnan (eds) Modern Medicine: Lay Perspectives and Experiences, London: UCL Press Ltd: 230-255.

Singer, M. and Baer, H.A. 1995 Critical Medical Anthropology, New York: Baywood Publishing Company Inc.

Tesh, S.N. 1988 Hidden Arguments: Political Ideology And Disease Prevention Policy, New Brunswick: Rutgers University Press.

Weston, W.W. and Brown, J.B. 1989 'The Importance of Patients' Beliefs', in M. Stewart and D. Roter (eds) Communicating With Medical Patients, Newbury Park: Sage Publications: 77-85.

Williams, G. and Popay, J. 1994 'Lay knowledge and the privilege of experience', in G. Williams (ed) Challenging Medicine, London: Routledge: 118-139.

Willis, E. 1994 Illness and Social Relations: Issues in the Sociology of Health Care, St Leonards: Allen and Unwin.

Wright-St Clair, R.E. 1989 A History of General Practice and of the Royal New Zealand College of General Practitioners, Wellington: The Royal New Zealand College of General Practitioners. 